\title{
SEKOLAH/MADRASAH BERKUALITAS DAN BERKARAKTER
}

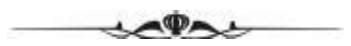

\author{
Oleh: Mustaqim \\ IAIN Walisongo Semarang
}

\begin{abstract}
Abstrak
Keberhasilan pendidikan Indonesia secara makro sangat ditentukan oleh jutaan institusi mikro yang bernama sekolah. Rangkaian jutaan sekolah itulah yang akan menentukan bangunan kualitas pendidikan di negara tercinta ini. Singkatnya, apabila mikro sekolah tersebut unggul, dapat dipastikan kualitas pendidikannya, bahkan sumber daya manusia, akan terdongkrak menjadi unggul pula. Selama ini, tidak jarang sekolah yang mengklaim dirinya sebagai sekolah unggulan. Beragam upaya dilakukan untuk mewujudkan hal tersebut, di antaranya melakukan sertifikasi ISO, menaikkan status sekolah menjadi SBI (Sekolah Berstandar Internasional), menyekolahkan tenaga pengajar ke jenjang magister (S2), dan lainnya. Bahkan, berdalih sebagai sekolah unggulan, siswa yang disaring pun hanya siswa yang memiliki kualifikasi akademik tinggi. Namun satu hal yang perlu diingat, bahwa pembangunan sekolah berkualitas juga dibutuhkan budaya sekolah yang berkualitas serta mantabnya karakter sekolah menuju peningkatan kualitas pendidikan yang berkelanjutan.
\end{abstract}

Kata Kunci: Sekolah Berkualitas, TQM, Budaya Mutu 


\section{A. Pendahuluan}

Sistem penjaminan mutu pendidikan di Indonesia sudah diatur dalam Peraturan Menteri Pendidikan Nasional No. 63 thn 2009, meliputi banyak hal, antara lain tentang batasan mutu, tujuan penjaminan mutu dan acuan tingkatan mutu, yang tertuang dalam beberapa pasal, antara lain :

Tujuan akhir penjaminan mutu pendidikan adalah tingginya kecerdasan kehidupan manusia dan bangsa sebagaimana dicita-citakan oleh Pembukaan UUD Negara Republik Indonesia Tahun 1945 yang dicapai melalui penerapan SPMP. (Psl. 2 ayat 1).

Ayat diatas dijelaskan sebagai berikut :

Tingginya kecerdasan kehidupan manusia dan bangsa sebagaimana dimaksud dalam pasal 2 ayat 1 mengacu pada mutu kehidupan manusia dan bangsa Indonesia yang komprehensif dan seimbang yang mencakup sekurang-kurangnya:

1. Mutu keimanan, ketakwaan, akhlak, dan kepribadian

2. Kompetensi intelektual, estetik, psikomotorik, kinestetik, vokasional, serta kompetensi kemanusiaan lainnya sesuai dengan bakat, potensi dan minat masing-masing

3. Muatan dan tingkat kecanggihan ilmu pengetahuan, teknologi dan seni yang mewarnai dan memfasilitasi kehidupan

4. Kreativitas dan inovasi dalam menjalani kehidupan

5. Tingkat kemandirian dan daya saing

Sekarang pertanyaan yang perlu dijawab atau dicari jawabannya atau alternatif jawabannya adalah seberapa jauh Permendiknas tersebut mampu mendorong kepada semua pelaku pendidikan dan yang terkait mampu mewujudkan pengelolaan lembaga pendidikan yang unggul dan tetap menjaga karakter yang unggul pula baik dalam prosesnya maupun unggul dalam produknya. Dalam buku statistik pendidikan Islam yang diterbitkan oleh Direktorat Jenderal Pendidikan islam pada tahun 2009/2010 tertera data akreditasi madrasah sebagai salah satu tolok ukur mutu. Untuk level Madrasah Ibtidaiyah ada 1.688 atau 7,6\%, sebanyak 9088 madrasah atau 40,9\% terakreditasi B dan sebanyak 7170 atau 32,3\% terakreditasi C, sisanya sebanyak 4293 Madrasah Ibtidaiyah atau 19,3\% belum terakreditasi. 
Jika madrasah yang terakreditai A dan B dijumlah ada 10.776 atau 48,5\% dianggap yang unggul, maka bisa ditarik kesimpulan bahwa Madrasah Ibtidaiyah yang belum unggul masih diatas $50 \%$.

Apalagi kalau yang dianggap Madrasah Ibtidaiyah unggul itu yang hanya terakreditasi A saja maka kecil sekali yaitu 7,6 \% kurang dari $10 \%$ atau $92.4 \%$ MI belum unggul atau belum bermutu, mengapa hal ini bisa terjadi? Siapa yang salah?

Ini perlu mencari jawabannya. Untuk level MTs.ada 1199 atau 8,6 \% MTs terakreditasi A, ada 5757 atau 41,1\% terakreditas B dan ada 3698 atau 26,3\% terakreditasi C, sisanya sebanyak 3368 atau 24,0 $\%$ belum terakreditasi, jika kaidah MTs unggul adalah yang terakreditasi A, maka ada 91,4\% MTs belum unggul/bermutu. Demikian pula pada jenjang MA, sebanyak 484 atau 8,2 \% terakreditasi A, terakreditasi B ada1879 atau 31,9\% dan terakreditasi C ada 1650 atau $27,9 \%$ dan selebihnya sebanyak 1884 atau $31,9 \%$ belum terakreditasi , jika indikator unggul atau bermutu sama dengan MI dan MTs, maka masih ada sekitar 91,8 \% masih belum unggul. Tampak jelas ada kesenjangan antara ideal dan realitas di lapangan maka tulisan ini akan mencoba membahas kajian yang terkait dengan pengelolaan sekolah atau menuju madrasah yang unggul dan tetap menjaga etika dan karakter bangsa sesuai cita-cita mulia kita bersama.

\section{B. Konsep Manajemen Mutu}

\section{De?nisi Mutu}

Edwin L. Artst, CEO Proctor and Gamble Company, mengatakan: "Pelanggan-pelanggan kami adalah mereka yang menjual dan juga menggunakan produk kami. Tujuan mutu terpadu adalah memahami kebutuhan mereka yang selalu berkembang, serta menggunakan pengetahuan tersebut untuk diterjemahkan ke dalam produkproduk dan pendekatan bisnis baru yang inovatif. Philip Crosby pakar kualitas yang lain, mencanangkan Program Zero De-fect (Kerusakan nol). Zero Defect merupakan komitmen pada kesuksesan dan mengurangi kesalahan. Program ini menekankan pentingnya sistem untuk selalu mengerjakan sesuatu secara benar dari awal. Di samping itu Philip Crosby memperkenalkan empat belas 
langkah mencapai kualitas (Philip Crosby's 14 step to quality). Philip Crosby's 14 step to quality adalah sebagai berikut :

\section{a. Management Commitment}

Inisiatif kualitas harus disetujui dari pimpinan oleh Senior Management

\section{b. Quality Improvement Team}

Jika setiap fungsi dalam organisasi potensial untuk menimbulkan kesalahan dan kegagalan kualitas, maka setiap bagian organisasi harus berpartisipasi dalam usaha peningkatan.

c. Quality Measurement (Pengukuran Kualitas)

Di dalam pengukuran terdapat data dari hasil inspeksi dan laporan tes, data statistik dan data umpan balik dari pelanggan. d. Cost of Quality

Biaya kualitas terdiri dari hal-hal yang berkaitan dengan biaya kesalahan, pekerjaan ulang, pembatalan, inspeksi dan pengujian. e. Quality Awareness.

Upaya menumbuhkan kesadaran pada setiap orang di dalam organisasi tentang kebutuhan program peningkatan kualitas.

f. Corrective Action

Supervisor memerlukan kerjasama dengan stafnya guna mengurangi kualitas yang buruk.

g. Zero Defects Planning

Program ini diperkenalkan dan dibimbing oleh Quality Improvement Team. Tim tersebut bertanggung jawab atas implementasi program ini.

h. Supervisor Trainning

Supervisor sangat berperan dalam proses peningkatan dan pelatihan ini dibutuhkan oleh mereka.

i. Zero Defect Day

Ini merupakan ide untuk menetapkan setiap hari adalah hari tanpa kesalahan dalam bekerja.

j. Goal Setting

Berkaitan dengan Zero Defect Day, perlu kiranya ditetapkan tujuan yang spesifi $\mathrm{k}$ dan dapat diukur.

k. Error-Cause Removal

Dengan menetapkan standar maka komunikasi sampai pada 
garis manajer yang tepat.

l. Recognation (Pengakuan)

Sesungguhnya orang bekerja bukan untuk uang, ada hal yang penting dari sekedar gaji yang besar yaitu adanya pengakuan atas prestasi dan kontribusi mereka.

m. Quality Councils (Dewan Kualitas)

Menetapkan adanya dewan kualitas. Dimana perannya untuk memonitoring efektivitas program dan meyakinkan bahwa proses peningkatan terus berlanjut.

n. Do it Over Again (Kerjakan Secara Terus Menerus)

Program kualitas senantiasa tidak pernah berakhir. Satu tujuan tercapai maka perlu dicapai program lain dan seterusnya.

Ada tokoh lain yang Senada,menyatakan; Managemen mutu (quality management), seperti yang dikemukakan di depan: "is management for continous improvement in quality from business view point", dengan kata lain "quality management is management of business for continous improvement in its performance". Dalam perkembangannya manajemen mutu sangat dikenal dengan istilah "total quality management” (TQM). Total Quality Management bukanlah seperangkat prosedur dan proses untuk memperbaiki kinerja dan meningkatkan mutu kerja. TQM adalah suatu cara lain dalam mengatur usahausaha orang banyak. Maksudnya adalah menyelaraskan usaha-usaha mereka sedemikian rupa sehingga orang-orang itu menghadapi tugasnya dengan penuh semangat dan berpartisipasi dalam perbaikan pelaksanaan pekerjaan. Total Quality Management adalah suatu pola manajemen yang berisi prosedur agar dalam organisasi setiap orang berusaha keras secara terus menerus memperbaiki jalan menuju sukses.

Penting juga diutarakan disini tentang teori dari tokoh utama W. Edwards Deming yang tertuang dalam Out of the Crisis yang dipublikasikan pada tahun 1982, berisi 14 poin, yaitu:

a. Ciptakan sebuah usaha peningkatan produk dan jasa dengan tujuan agar bisa kompetitif.

b. Adopsi falsafah baru, membuat perubahan dan mengadopsi metode kerja yang baru.

c. Hindari ketergantungan pada inspeksi massa untuk mencapai 
mutu. Manajemen harus melengkapi staf-staf mereka dengan pelatihan tentang alat-alat statistik dan teknik-teknik yang dibutuhkan mereka untuk mengawasi dan mengembangkan mutu mereka sendiri

d. Mengembangkan hubungan dekat dari berjangka panjang dengan pensuplai, dan sebaliknya pensuplai tunggal, dan bekerjasama dengan mereka dalam mutu komponen.

e. Tingkatkan secara konstan sistem produksi dan jasa, untuk meningkatkan mutu dan produktivitas.

f. Lembagakan pelatihan kerja. Lebih penting lagi adalah melatih dengan standar terbaik dalam kerja.

g. Lembagakan kepemimpinan. Kepemimpinan yang mendorong peningkatan proses produksi barang dan jasa yang lebih baik.

h. Hilangkan rasa takut, agar setiap orang dapat bekerja secara efektif.

i. Uraikan kendala-kendala

j. Hapuskan slogan, desakan dan target serta tingkatkan produktivitas tanpa menambah beban kerja.

k. Hapuskan standar kerja yang menggunakan quota numerik.

1. Hilangkan kendala-kendala yang merampas kebanggaan karyawan atas keahliannya.

m. Lembagakan aneka program pendidikan yang meningkatkan semangat dan peningkatan kualitas kerja.

n. Tempatkan setiap orang dalam titik kerja agar dapat melakukan transformasi.

\section{Sekolah Berkualitas Dan Berkarakter}

\section{Batasan}

Jika kita melacak sejarah defi nisi tentang sekolah/madrasah berkualitas/atau unggul dan berkarakter akan ketemu garis kemiripan seperti di bawah ini ;

Sekolah berkualitas/unggul adalah sekolah yang dikembangkan untuk mencapai keunggulan dalam keluaran (output) pendidikannya. Untuk mencapai keunggulan tersebut maka masukan (input), proses pendidikan, guru dan tenaga kependidikan, manajemen, layanan 
pendidikan, serta sarana penunjangnya harus diarahkan untuk menunjang tercapainya tujuan tersebut. Sedangkan dalam Permendik-nas No.63 tahun 2009, dijelaskan bahwa;

Mutu pendidikan adalah tingkat kecerdasan kehidupan bangsa yang dapat diraih dari penerapan Sistem Pendidikan Nasional.

Selanjutnya dalam ayat lain dinyatakan bahwa; Tujuan akhir penjaminan mutu pendidikan adalah tingginya kecerdasan kehidupan manusia dan bangsa sebagaimana dicita-citakan oleh Pembukaan UUD Negara Republik Indonesia Tahun 1945 yang dicapai melalui penerapan SPMP. Ayat di atas dijelaskan sebagai berikut:

Tingginya kecerdasan kehidupan manusia dan bangsa sebagaimana dimaksud dalam pasal tersebut mengacu pada mutu kehidupan manusia dan bangsa Indonesia yang komprehensif dan seimbang yang mencakup sekurang-kurangnya:

a. Mutu keimanan, ketakwaan, akhlak, budi pekerti, dan kepribadian.

b. Kompetensi intelektual, estetik, psikomotorik, kinestetik, vokasional, serta kompetensi kemanusiaan lainnya sesuai dengan bakat, potensi dan minat masing-masing.

c. Muatan dan tingkat kecanggihan ilmu pengetahuan, teknologi dan seni yang mewarnai dan memfasilitasi kehidupan.

d. Kreativitas dan inovasi dalam menjalani kehidupan.

e. Tingkat kemandirian dan daya saing.

Selanjutnya dalam Pasal 10 ayat 1 dan ayat 2 disebutkan bahwa penjaminan mutu pendidikan oleh satuan atau program pendidikan ditujukan untuk memenuhi tiga tingkatan acuan mutu, yaitu: SPM, SNP, Strandar mutu pendidikan di atas SNP.

\section{Ciri-ciri sekolah berkualitas/unggul dan berkarakter}

Dimensi-dimensi keunggulan sebagai ciri sekolah unggul, adalah sebagai berikut :

a. Masukan (imput) yaitu siswa diseleksi secara ketat dengan menggunakan kriteria tertentu dan prosedur yang dapat dipertanggungjawabkan. Kriteria yang dimaksud adalah: (1) prestasi bela- 
jar superior dengan indikator angka rapor, Nilai Ebtanas Murni (NEM), dan hasil tes prestasi akademik; (2) skor psikotes yang meliputi inteligensi dan kreativitas; (3) tes fisik, jika diperlukan.

b. Sarana dan prasarana yang menunjang untuk memenuhi kebutuhan belajar siswa serta menyalurkan minat dan bakatnya, baik dalam kegiatan kurikuler maupun ekstra kurikuler.

c. Lingkungan belajar yang kondusif untuk berkembangnya potensi keunggulan menjadi keunggulan yang nyata baik lingkungan fisik maupun sosial-psikologis.

d. Guru dan tenaga kependidikan yang menangani harus unggul baik dari segi penguasaan materi pelajaran, metode mengajar, maupun komitmen dalam melaksanakan tugas. Untuk itu perlu disediakan intensif tambahan bagi guru berupa uang maupun fasilitas lainnya seperti perumahan.

e. Kurikulumnya diperkaya dengan pengembangan dan improvisa-si secara maksimal sesuai dengan tuntutan belajar peserta didik yang memiliki kecepatan belajar serta motivasi belajar yang lebih tinggi dibanding dengan siswa seusianya.

f. Kurun waktu belajar lebih lama dibandingkan sekolah lain. Karena itu perlu ada asrama untuk memaksimalkan pembinaan dan menampung para siswa dari berbagai lokasi. Di kompleks asrama perlu ada sarana yang bisa menyalurkan minat dan bakat siswa seperti perpustakaan, alat-alat olah raga, kesenian dan lain-lain yang diperlukan.

g. Proses belajar mengajar harus berkualitas dan hasilnya dapat dipertanggungjawabkan (accountable) baik kepada siswa, lembaga, maupun masyarakat.

h. Sekolah unggul tidak hanya memberikan manfaat kepada peserta didik di sekolah tersebut, tetapi harus memiliki resonansi sosial kepada lingkungan sekitarnya.

i. Nilai lebih sekolah unggul terletak pada perlakuan tambahan di luar kurikulum nasional melalui pengembangan kurikulum, pro-gram pengayaan dan perluasan, pengajaran remidial, pelayanan bimbingan dan konseling yang berkualitas, pembinaan kreativitas dan disiplin. 
Hasil Penelitian yang telah dilakukan oleh para ahli sebagaimana dikutip oleh Umaidi (2004) tentang sekolah efektif/unggul antara lain dilakukan oleh:

1. Edmonds, Brookover, Lezotte, dan Fredericksen mendeskripsikan faktor-faktor atau variabel yang berkorelasi terhadap keefektifan sekolah sebagai berikut: 1) penekanan pada penguasaan anak terhadap keterampilan dasar; 2) harapan yang tinggi terhadap anak; 3) kepemimpinan administratif yang kuat; 4) sering memonitor siswa; dan 5) iklim yang tertib/teratur mendukung proses belajar.

2. Purkey dan Smith mengidentifi kasi sembilan karakteristik yang bersifat organisasi dan empat karakteristik yang bersifat proses, yaitu :

a. Manajemen berbasis sekolah (School site management)

b. Kepemimpinan instruksional (instructional leadership)

c. Kestabilan staf (staff stability)

d. Kurikulum yang jelas dan pengorganisasian (curriculum articulation and organization)

e. Pengembangan staf pada lingkup sekolah (school wide staff development)

f. Keterlibatan dan dukungan orang tua (parental involvement and support)

g. Penghargaan/pengakuan keberhasilan akademik pada lingkup sekolah (school wide recognition of academic success)

h. Memaksimalkan waktu belajar (maximized learning time)

i. Dukungan kantor distrik (district support)

Empat karakteristik prosesnya adalah :

a. Perencanaan bersama dan hubungan yang bersahabat (collaboration planning and collegial relationship)

b. Perasaan sebagai satu komunitas (sense of community)

c. Tujuan akhir yang jelas dan harapan yang tinggi (clear goals and high expextation)

d. Tertib dan disiplin (order and discipline).

3. Gauthier, Shoemaker, Villanova dan lainnya yang terlibat dalam "The Connecticut School Efectiveness Project" mengemukakan tujuan 
H. Mustaqim

korelasi (karakteristik), yaitu :

a. Keteraturan, ketertiban dan keamanan suasana lingkungan (safe and orderly environment)

b. Misi sekolah yang jelas (clear school mission)

c. Kepemimpinan instruksional (instructional leadership)

d. Hadapan yang tinggi (bigh expextations)

e. Kesempatan untuk belajar dan kesempatan anak untuk memanfaatkan waktu belajar (opportunity to learn and student time on task.)

f. Sering dilakukan monitor atas kemajuan siswa (frequent monitoring of student progress), dan

g. Hubungan positif antara rumah dan sekolah (positive bomeschool relation).

4. Levine dan Lezotte memproposisikan karakteristik yang agak berbeda tentang sekolah yang tergolong efektif, meskipun sebagian besar sama, sebagai berikut :

a. Kultur dan iklim sekolah yang produktif (productive school climate and culture)

b. Fokus pada pencapaian keterampilan pokok belajar siswa (focus on student aquisition of central learning skills)

c. Monitoring kemajuan siswa secara memadai (Appropriate monitoring of student progress)

d. Pengembangan staf yang berorientasi praktis di sekolah (Practice oriented staff development at the school site)

e. Kepemimpinan yang bagus (Outstanding leadership)

f. Keterlibatan orang tua yang menonjol (Salient parent involvement)

g. Pengaturan pembelajaran dan pelaksanaannya efektif (Effective instructional arrangement and implementation)

h. Harapan tinggi terhadap siswa, baik secara operasional maupun persyaratan baginya (high operationalized expectation and requirement)

i. Dan seterusnya yang mungkin berkorelasi.

Selanjutnya perlu juga ditambah disini tentang tawaran untuk mengukur mutu sekolah dengan daftar uji penilain diri dari Edward Sallis sebagai berikut : 
a. Akses

1) Hubungan dengan pelanggan

a) Hubungan awal yang jelas dengan pelanggan

b) Penerimaan yang baik

c) Respon telepon yang cepat

d) Petunjuk dan pedoman yang siap-sedia

e) Survei tentang respon pengunjung terhadap sambutan yang mereka terima

f) Tanda-tanda petunjuk yang jelas

2) Akses yang terbuka

a) Jalan landai dan lift khusus untuk para penderita tuna-daksa

b) Bahasa awam yang digunakan dalam tanda-tanda petunjuk dan literatur

b. Layanan bagi pelanggan

1) Petunjuk dan Bimbingan

a) Layanan informasi dan bimbingan yang siap-sedia

b) Bimbingan masuk yang tepat bagi calon pelajar

c) Petunjuk lanjut yang siap-sedia

d) Petunjuk karir yang siap-sedia

e) Kesejahteraan dan konseling pelajar yang mudah didapat

2) Sumberdaya dalam proses belajar

a) Perpustakaan dan pusat sumberdaya yang memadai

b) Sumberdaya belajar yang terbuka

c) Fasilitas komputer yang baik

3) Fasilitas umum

a) Fasilitas kantin yang siap dan baik

b) Fasilitas olahraga yang memadai

c) Fasilitas relaksasi yang baik dan memadai

d) Kesempatan bagi para pelajar untuk mengorganisir aktivitasnya.

c. Kepemimpinan

1) Kepala sekolah

a) Kepala sekolah memiliki dan menyebarluaskan visi yang jelas 
b) Kepala sekolah menjalankan tugas

c) Kepala sekolah mengenal para staf

d) Kepala sekolah mengenal para pelajar

e) Kepala sekolah menjalankan kepemimpinan yang baik

f) Kepala sekolah menempatkan mutu sebagai prioritas

2) Nilai-nilai
a) Misi yang jelas dan bisa dipahami
b) Kebijakan yang memberikan "kesempatan yang sama"
c) Staf dan pelajar memahami etos sekolahnya
d) Komitmen yang kuat terhadap kebutuhan komunitas

d. Lingkungan dan Sumberdaya Fisik

1) Bangunan, ruang kelas dan ruang lokakarya

a) Bersih dan atraktif

b) Sesuai dengan tujuan

c) Enak dipandang, nyaman dan membantu proses belajar-mengajar

2) Lingkungan belaja yang mendukung

a) Tata letak ruang yang menarik bagi pelajar

b) Lingkungan belajar yang terencana dan terorganisir dengan baik

3) Kesehatan dan keselamatan

a) Pelajar terjaga dari segala bentuk kecelakaan

b) Kebijakan kesehatan dan keselamatan yang diawasi dengan baik

4) Kontrol dan alokasi sumberdaya

a) Kontrol sumberdaya yang efektif

b) Sumberdaya terkontrol oleh yang menggunakannya

e. Pembelajaran Efektif

1) Ketepatan Metode Pembelajaran

a) Strategi pembelajaran dan pengajaran yang sesuai dengan tujuan

b) Variasi model pembelajaran baik dan menarik

c) Strategi pembelajaran dan pengajaran yang sesuai dengan kriteria oyektif

d) Strategi pembelajaran dan pengajaran yang sesuai dengan respon pelajar 
e) Pembelajaran yang bersifat fokus pada pelajar

f) Pelajar ikut bertanggungjawab terhadap proses belajar mereka sendiri

g) Mengutamakan pembelajaran melalui skala prioritas

h) Metode evaluasi digunakan untuk mengetahui respon pelanggan

i) Tujuan akhir yang baik dapat diraih para pelajar

2) Ketepatan portofolio pembelajaran

a) Ketepatan portofolio dengan kebutuhan pelajar

b) Materi program yang relevan dan modern

c) Respon yang cepat terhadap pengembangan program baru

d) Evaluasi klien terhadap relevansi penawaran

e) Penyampaian program dengan baik terhadap pemilik lapangan kerja

3) Pengawasan dan Evaluasi

a) Umpan-balik dari pelajar secara berkala

b) Umpan-balik dari pelanggan lain secara berkala

c) Kuesioner pelajar dan komunitas yang digunakan secara tepat

d) Sistem formal institusi untuk tinjauan ulang dan evaluasi

e) Umpan-balik digunakan sebagai dasar untuk membuat kebijakan

f. Pelajar

1) Kepentingan pelajar

a) Tanda-tanda petunjuk yang jelas

b) Toilet yang bersih dan baik

c) Buku panduan dan pedoman yang siap

d) Staf sangat komunikatif dengan para pelajar

e) Sama sekali tidak ada kendala yang dibuat-buat

f) Layanan pelajar yang baik

g) Transportasi yang baik

h) Fasilitas rekreasi dan olahraga yang tersedia

2) Kepuasan pelajar

a) Laporan yang baik tentang staf dan pelajar 
H. Mustaqim

b) Kegembiraan dan kepuasan pelajar dibuktikan melalui survei dan kuesioner

c) Pelajar merasa bangga terhadap tugas mereka

d) Pelajar selalu mendapat informasi

e) Pandangan pelajar selalu terdata

g. Staf

1) Sikap dan Motivasi

a) Berkomitmen dan berpengetahuan

b) Berfokus pada pelajar

c) Bertanggungjawab terhadap mutu

d) Merasa bangga terhadap kinerja mereka

e) Selalu merasa senang

f) Merespon kebutuhan individual

2) Tim kerja

a) Berkomitmen terhadap tim dan kerja tim

b) Terlatih dalam keterampilan

c) Memiliki kemampuan kerja tim yang kuat

d) Memiliki ide yang jelas tentang batasan otoritas

e) Memiliki sumberdaya yang mendukung peningkatan mutu

f) Menghargai dan mendukung praktik-praktik kerja yang baik

g) Berkonsultasi tentang kebijakan secara teratur

3) Pengembangan staf

a) Institusi berkomitmen terhadap pengembangan staf

b) Pengembangan staf bersikap pro-aktif dan secara jelas menegaskan kebutuhan institusi

c) Pengembangan staf memiiki tinjauan ulang tentang kebutuhan individu

d) Pengembangan staf mendapatkan sumberdaya yang cukup

e) Pengembangan staf merupakan bagian dari prioritas institusi

f) Pengembangan staf mencakup semua staf

g) Pengambangan staf untuk TQM

4) Fasilitas staf 

a) Ruang kerja yang baik
b) Peralatan dan fasilitas yang tepat dan memadai
c) Kesempatan untuk melakukan diskusi dan debat profesional

h. Relasi Eksternal

\section{1) Pemasaran}

a) Strategi pemasaran yang logis

b) Riset pasar

c) Mencari pandangan positif pra pelanggan

d) Penyebaran kuesioner bagi para pelajar dan para pemilik lapangan kerja

\section{2) Komunitas}

a) Hubungan baik dengan komunitas yang relevan

b) Pandangan komunitas dimanfaatkan secara berkala

c) Hubungan kuat dengan partner pendidikan atau partner bisnis

i. Keorganisasian

\section{1) Perencanaan strategis}

a) Institusi memiliki tujuan dan cita-cita yang luas

b) Staf di semua level menyadari arah institusi

c) Institusi memiliki perencanaan strategi yang tertulis

d) Perencanaan mengidentifi kasi cara staf agar dapat memberikan kontribusi kesuksesan

\section{2) Kultur Organisasi}

a) Struktur yang sederhana dan ramping

b) Otoritas didelegasikan

c) Perubahan adalah bagian dari kultur

d) Statemen umum tentang pengarahan

e) Komitmen yang kuat untuk melakukan evaluasi dan tinjauan ulang

f) Didasarkan pada kerja tim

j. Standar-standar

1) Standarkeras

a) Hasil ujian yang memuaskan dan kesuksesan pelajar

b) Tingkat kemajuan yang tinggi

c) Penggunaan sumberdaya-sumberdaya secara efektif 
d) Umpan-balik komunitas dan pelajar yang didasarkan pada koleksi yang sistematis

e) Kontrol dana yang efektif

2) Standar lunak

a) Suasana yang menyenangkan

b) Kesejahteraan pelajar merupakan sebuah prioritas

c) Layanan pelanggan terbukti secara nyata

d) Lingkungan yang bersahabat

e) Komitmen terhadap para pelajar dengan semua keahlian

3) Aplikasi standar yang benar

a) Institusi tidak mengukur diri hanya dengan prioritasprioritas keras semata.

\section{Kesimpulan}

Dari beberapa pandangan para ahli yang dipaparkan diatas bisa disarikan sebagai berikut:

Sekolah berkualitas/unggul dan berkarakter memiliki indikator :

1. Perumusan visi, misi dan target mutu yang jelas dipahami semua pihak yang terlibat pimpinan,guru, karyawan peserta didik,orang tua dan komite sekolah/madrasah

2. Kepemimpinan sekolah yang kuat, memperoleh dukungan dari semua pihak terkait

3. Memiliki motivasi dan Harapan prestasi yang tinggi, mampu bersaing secara terus menerus

4. Pengembangan dan pelatihan tenaga pendidik dan kependidikan sekolah yg terencana secara terus-menerus

5. Evaluasi hasil belajar dan faktor-faktor yang mempengaruhinya untuk penyempurnaan proses pembelajaran

6. Komunikasi dan dukungan orang tua dan masyarakat

7. Komitmen seluruh warga sekolah akan pentingnya peningkatan mutu.

8. Lingkungan sekolah yang aman dan tertib

9. Membangun jaringan kerjasama dengan pihak terkait secara terus-menerus. 


\section{DAFTAR PUSTAKA}

Sallis, Edward, 2007, Total Quality Management in Education.

Aulia, Nuansa, 2010, Himpunan Perundang-undangan Republik Indonesia tentang Sistem Pendidikan Nasional, Bandung.

Direktorat Jenderal Pendidikan Islam, 2010, Buku Statistik Pendidikan Islam, Jakarta.

Ekosusilo, Madyo, 2003, Sistem Nilai Dalam Budaya Organisasi Sekolah Pada Sekolah Unggul, Malang.

Fandy Tjiptono \& Anastasia Diana, 2003, Total Quality Management, Yogyakarta, Penerbit Andi.

Umaedi, 2004, Manajemen Mutu Berbasis Sekolab/ Madrasah (MMBS/M), Jakarta: Pusat Kajian Manajemen Mutu Pendidikan. 

